\title{
Unobservable information and behavioural patterns in futures markets: The case for Brent Crude Oil, Gold and Robusta Coffee contracts
}

\author{
Spyros Spyrou \\ Athens University of Economics and Business, Department of Accounting and \\ Finance, Patission 76, 10434, Athens, Greece. Tel. +0030 2108203169 ; \\ E-mail: sis@hol.gr
}

Received: 9th January, 2006

Spyros Spyrou holds a PhD in Financial Economics from Brunel University and is currently a senior lecturer at the Athens University of Economics \& Business, Athens, Greece. Before that he was a lecturer at the University of Durham. He has published several papers in academic journals, including Journal of Business Finance \& Accounting (forthcoming), European Financial Management, The Manchester School, Applied Economics and Journal of Economic Development, among others.

\section{Practical applications}

The paper shows that investors in commodity futures contracts may not react efficiently to price shocks, that proxy for the arrival of unobservable information. For example, the results indicate that, on average, investors in the IBE Brent Crude Oil Futures contract tend to overreact to positive price shocks. However, an important question in any study of investor behaviour is whether the findings can be applied in practice. In other words, if the detected patterns are real market inefficiencies then they must lead to abnormal returns. To this end, the paper also investigates whether a zero-investment trading strategy based on the findings could produce profit for the IPE Brent Crude Oil Futures contracts. For instance, a trader could (a) borrow the margin, (b) short a contract on a positive shock day when investors overreact, (c) during the price reversal few days later close the position and repay the loan. It is demonstrated that if a trader consistently followed the strategy for the 2000-2005 period he or she would enjoy significant gains.

\begin{abstract}
The paper shows that investors in commodity futures contracts may not react efficiently to information contained in price shocks. More specifically, the results suggest that, between 1990 and 2005, investors in the IPE Brent Crude Oil Futures contract overreacted to positive market shocks, investors in the CMX
\end{abstract}

Gold Futures contract underreacted to negative price shocks, and investors in the LIFFE Robusta Coffee Futures contract underreacted to positive price shocks. Further analysis indicates that, for the oil and gold contracts, this behaviour is contained in the sub-period between 2000 and 2005, while for the coffee contract it is contained in the sub-period between 1991 and
Derivatives Use, Trading \& Regulation, Vol. 12 No. 1/2, 2006, pp. 48-59

c) Palgrave Macmillan (c) Pal
Ltd 
1994. A zero-investment trading strategy for the IPE Brent Crude Oil Futures contract generates significant arbitrage profits, indicating that these pricing inefficiencies may be exploitable in practice.

\section{INTRODUCTION}

The empirical results of DeBondt and Thaler ${ }^{1}$ challenge the notion of information efficiency and investor rationality, and demonstrate that abnormal profits are possible using historical information owing to the tendency of investors to overreact to information. Many studies also document serial correlation and price reversals in stock returns (see, among others, Jegadeesh ${ }^{2}$ and Baytas and Cakici $^{3}$ ) and short-term and/or intra-day inefficient investor reaction following days on which extreme events took place. For instance, Lasfer et al. ${ }^{4}$ find that, for 39 international stock market indexes, on average, positive (negative) shocks are followed by subsequent large positive (negative) abnormal returns in both developed and emerging equity markets, consistent with the short-term underreaction hypothesis. Many authors attempt to explain these phenomena with investor psychology (see, for example, Barberis et al. ${ }^{5}$ ) and present different channels through which investor psychology can lead to inefficiencies in securities' returns. ${ }^{6}$

Although price reversals and investor reaction to information have been extensively studied for stock and stock indexes, relatively few studies examine the reaction of investors to information in futures markets. Futures markets are important for price discovery and are expected to increase the overall level of market informativeness. Furthermore, since (a) transaction costs are typically smaller, and the capital committed is much lower than that of a cash transaction in the same asset, and (b) futures market participants are assumed to be better informed and more sophisticated (usually professional and institutional investors ${ }^{7}$ ), it should be expected that futures markets would process information more efficiently than cash markets would. Indeed, Ederington and Lee $^{8}$ investigate the price adjustment following scheduled macroeconomic news releases and find that the adjustment process is completed within minutes of the information release. There is also evidence to suggest, however, that futures investors may at times react inefficiently to information: Gay et al. ${ }^{9}$ find that investors in commodity futures overreact to negative news at market open and then reverse during trading, while Grant et al. ${ }^{10}$ employ the 'lead' contract on the S\&P500 Futures and find significant intra-day price reversals following large price changes in the market open. ${ }^{11}$ This paper investigates the short-term reaction of commodity futures investors to price shocks (extreme events). Price shocks serve as proxies for the arrival of unobservable information to the market. To anticipate the results, investors in oil futures seem to overreact to positive market shocks, while investors in gold futures underreact to negative market shocks. This behaviour is more significant during the most recent period (2000-2005). A zero-investment trading strategy for the IPE Brent Crude Oil Futures contract generates 
significant arbitrage profits, indicating that these pricing inefficiencies may be exploitable in practice.

\section{DATA AND METHODOLOGY}

For the empirical analysis continuous daily settlement prices on three important commodity futures contracts are employed. The contracts are the IPE Brent Crude Oil Futures contract, the LIFFE Robusta Coffee Futures contract, and the CMX Gold 100 $\mathrm{Oz}$ Futures contract. The data cover the period between July 1990 and April 2005 (3,850 observations for each contract), except for the coffee contract, where the data begin in March 1991 (3,673 observations) and are collected from Datastream (continuous series). A positive price shock is identified when the daily contract return is above two standard deviations the average daily contract return computed over the $(-60$ to -11$)$ days before that day, and a negative shock day occurs when the contract return is below two standard deviations the average daily contract return computed over the $(-60$ to -11) days before the day of the price shock. ${ }^{12}$ The abnormal return of contract $i$ on day $t\left(A R_{i t}\right)$ is computed as the difference between the contract $i$ return on day $t\left(r_{i t}\right)$ and the average return of the 50-day window ending ten trading days prior to day $t\left(E\left(r_{i t}\right)\right)$, that is: $A R_{i, t}=r_{i, t}-E\left(r_{i, t}\right)$. The cumulative abnormal return (CAR) for the next 1, 2, $3, \ldots, 40$ days is computed for each contract and each shock by summing the daily abnormal returns, and the average CAR (ACAR) for each type of shock is calculated by averaging the CARs for each contract and each shock. ${ }^{13}$ The statistical significance of the ACARs is evaluated with the $t$-statistic: $t=\overline{\mathrm{ACAR}} / \sigma / \sqrt{N}$, where $\sigma$ is the standard deviation of the CARs, and $N$ is the number of CARs from which the average CAR is estimated.

If investors react efficiently to information, all information contained in a shock is incorporated immediately in equity prices, and no return reversal or momentum should be observed on the day (days) following the particular event; as a result ACARs should be close to zero (and statistically insignificant). If negative (positive) shocks are followed by price increases (declines) during the following day (days), however, investors overreact to the arrival of information and correct their behaviour later; as a result, statistically significant ACARs of the opposite sign to the shock should be observed following the extreme event. Similarly, if large one-day price declines (increases) are followed by declines (increases) in prices the following day (days), investors underreact to the arrival of new information; as a result, statistically significant ACARs of the same sign to the shock should be observed following the extreme event.

In addition, in order to investigate whether the size of CARs following the shock is related to the shock day return, the CARs are regressed on the shock day abnormal returns as follows:

$$
C A R_{t+i}=a+b A R_{t}
$$

In (1) $C A R_{t+i}$ is the CAR at day $t+i$, and $A R_{t}$ is the abnormal return on the 
Table 1: Market reaction to shocks for commodity futures contracts (1990-2005)

Brent Crude Oil

Panel A: Negative shocks

No. shocks

AAR on shock day

AAR - Day 1

ACAR - Day 2

ACAR-Day 3

ACAR-Day 4

ACAR-Day 5

ACAR-Day 10

ACAR - Day 20

ACAR-Day 30

ACAR-Day 40

No. shocks

AAR on shock day

AAR - Day 1

ACAR-Day 2

ACAR-Day 3

ACAR-Day 4

ACAR-Day 5

ACAR-Day 10

ACAR - Day 20

ACAR-Day 30

ACAR-Day 40
38

$-0.0492(-15.06)^{\star}$

$-0.0015(-0.4445)$

$-0.0003(-0.0626)$

$-0.0045(-0.6423)$

$-0.0069(-0.8662)$

$-0.0096(-0.9848)$

-0.0135 (-1.1458)

$-0.0151(-0.8683)$

$-0.0083(-0.3878)$

0.0009 (0.0397)

Panel B: Positive shocks

$$
\begin{aligned}
& 37 \\
& -0.0198(-11.3330)^{\star} \\
& -0.0007(-0.7374) \\
& -0.0010(-0.6301) \\
& -0.0028(-1.6620)^{\star \star} \\
& -0.0069(-2.7264)^{\star} \\
& -0.0062(-2.7565)^{\star} \\
& -0.0092(-2.4188)^{\star} \\
& -0.0183(-3.4995)^{\star} \\
& -0.0087(-1.0791) \\
& -0.0047(-0.5904)
\end{aligned}
$$

$$
0.0484(13.84) \text { * }
$$$$
-0.0025(-0.7928)
$$$$
-0.0036(-0.9643)
$$$$
-0.0070(-1.3994)
$$$$
-0.0115(-2.3611) \star
$$$$
-0.0118(-1.6709)^{\star \star}
$$$$
-0.0235(-2.0918)^{\star}
$$$$
-0.0180(-1.2680)
$$$$
-0.0207(-1.0891)
$$$$
-0.0156(-0.8112)
$$

40

$0.0184(11.2572) \star$

$-0.0004(-0.3080)$

$0.0006(0.4260)$

$0.0008(0.5195)$

0.0017 (0.6491)

0.0051 (1.0926)

0.0088 (1.3607)

$0.0043(0.7060)$

$-0.0094(-1.3480)$

$-0.0109)(-1.2995)$
Robusta Coffee

37

$-0.0524(-9.8403)^{\star}$

$-0.0005(-0.1216)$

$0.0038(0.6632)$

$0.0033(0.4842)$

0.0090 (1.1569)

0.0089 (1.0003)

0.0154 (1.2009)

0.0244 (1.2983)

$0.0396(1.8294) \star \star$

$0.0354(1.5681)$

30

$0.0474(20.825)^{\star}$

$0.0016(0.4593)$

$0.0088(1.7498) \star \star$

$0.0111(1.6386) \star \star$

$0.0133(1.8129) \star \star$

$0.0166(1.9487)^{\star}$

$0.0206(1.5451)$

$0.0138(0.7953)$

$0.0170(0.8951)$

$0.0302(1.2847)$ event day $t$. This equation provides important information. For example, a statistically significant positive relationship between the event day abnormal return and the period $C A R$ will suggest that the larger the initial shock is, the more sizeable the following abnormal returns will be, and vice versa.

\section{RESULTS}

Table 1 presents returns for both negative shock days (Panel A) and positive shock days (Panel B), for the three sample contracts, as well as the following abnormal returns for up to 40 days following the event. For example, in Panel A, the first row presents the number of negative shocks 
per contract, the second row presents the average shock day abnormal return, ie the average market reaction, and rows 3-11 present the average CARs for days 1, 2, 3, $4,5,10,20,30$ and 40 following the shock. Note that the number of negative shocks during the sample period is similar for the three contracts (37-38 shocks). The average abnormal return on a negative shock day is -4.92 per cent for the Brent Crude Oil Futures contract, -1.98 per cent for the Gold Futures contract, and -5.24 per cent for the Robusta Coffee Futures contract. Note that, for the oil and coffee contracts, the $t$-statistics on the ACARs following the shock are not statistically significant, indicating that ACARs are not statistically different from zero (at the 5 per cent level of significance). In other words, it seems that all information contained in a negative shock is incorporated, on average, in prices within the same day. For the gold contract, however, ACARs become statistically significant three days after the negative shock and remain significant up to 20 days following the event. For example, the ACAR on day 20 is -1.83 per cent with a $t$-statistic of $(-3.4995)$. The negative sign on the ACARs suggests that investors in this contract underreact, on average, to information contained in negative shocks. The results in Panel B show that the average abnormal return on a positive shock day is 4.84 per centfor the Brent Crude Oil Futures contract, 1.84 per cent for the Gold Futures contract, and 4.74 per cent for the Robusta Coffee Futures contract. Investors in the Gold Futures contract appear to react efficiently to this type of information. This is not the case for the oil and coffee contracts, however: for the former, ACARs become statistically significant by day 4 and remain significant until day 10 (for example, the ACAR on day 10 is -2.35 per cent with a $t$-statistic of -2.0918). Also, a positive shock day is followed by negative ACARs, which indicates a reversal and overreaction to information. For the latter, ACARs become statistically significant on day 2 and remain significant until day 10 (for example, the ACAR on day 10 is 1.66 per cent, with a $t$-statistic of -1.9487), and the positive sign of the ACARs following a positive shock indicates investor underreaction to information.

Since the sample period is rather long, it is crucial to determine whether this investor behaviour varies during the sample period. To this end, the sample period was split into three sub-periods and investor reaction to positive and negative extreme events was re-estimated. The sub-periods are 1990-1994, 1995-1999 and 2000-2005. The results are reported in Table 2 and, for the oil contract (Panel C), the analysis indicates that investors react efficiently to extreme events for the first two sub-periods. During the last sub-period, however, there is strong evidence of investor overreaction to positive shocks, as ACARs are negative and statistically significant at 5 per cent. For example, three days after a positive shock, CARs are, on average, -1.85 per cent, which grows to -4.04 ten days after the shock. For the gold futures contract (Panel A), the sub-period analysis reveals a similar picture, as ACARs are statistically insignificant at 5 per cent for the first two sub-periods and for both type 


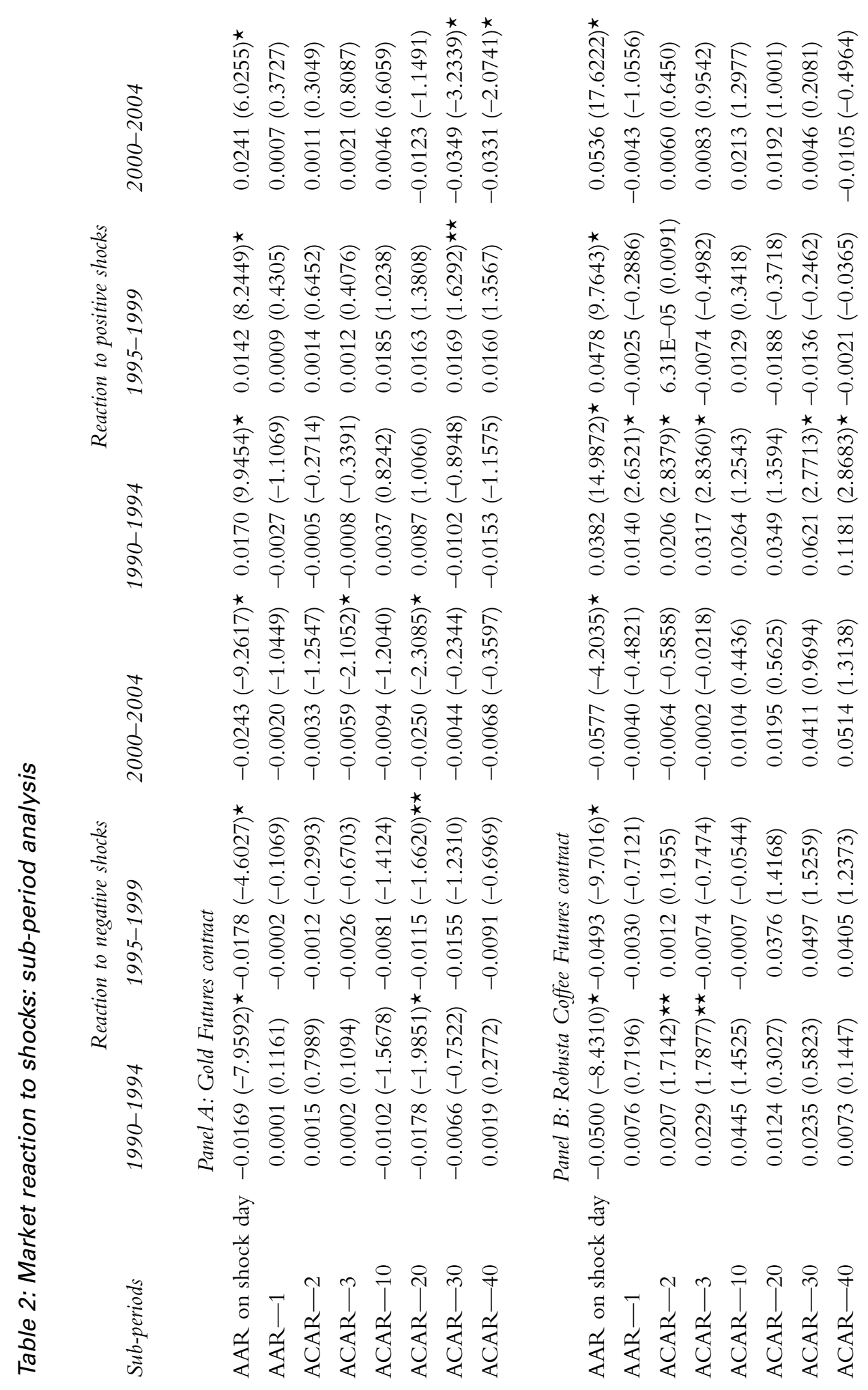




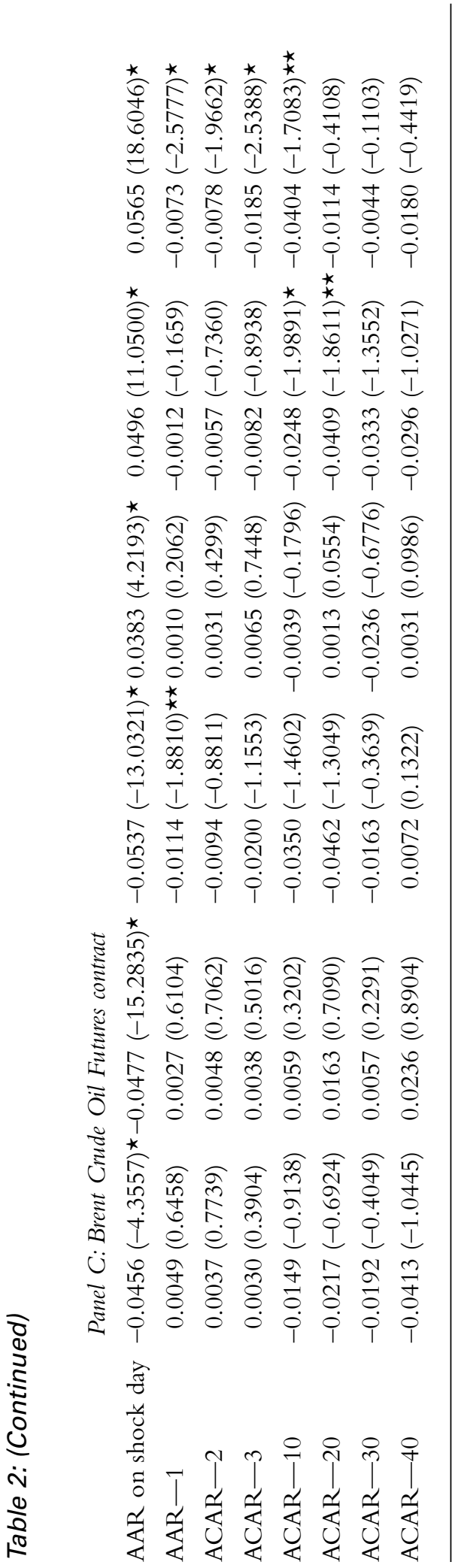


of shocks. For the last sub-period, however, there is evidence of underreaction to negative shocks; for example, the four-day ACAR following a negative shock is -1.3 per cent ( $t$-statistic -2.6810). For the coffee contract (Panel B), the situation is different, ie investors appear to react efficiently during the last decade, but there is strong evidence of underreaction to positive shocks during the period 1991-1994. Overall the sub-period analysis indicates that the inefficient investor behaviour evidenced in the previous sub-section is a phenomenon that occurs mainly during the recent period between 2000 and 2005 for investors in the Gold and Brent Crude Oil Futures contracts.

Table 3 reports regression results from equation (1) for the three series for ACARs of $1,5,10,20,30$ and 40 days following the extreme event. The aim here is to investigate whether the size of CARs following the shock is related to the shock day return. For the Brent Crude Oil Futures contract (Panel C), the only statistically significant coefficients on the independent variable is for positive shocks, as expected based on the above evidence. More specifically, the coefficient on the average abnormal return the first day after a positive shock $\left(\mathrm{AAR}_{t+1}\right)$ is negative and statistically significant at the 5 per cent level (t-statistic -2.2243) while the coefficient on the ACAR for the tenth day after a positive shock $\left(\mathrm{AAR}_{t+1}\right)$ is also negative and statistically significant at the 5 per cent level (t-statistic -2.7919). This indicates that the size of CARs following the shock is negatively related to the shock day return, ie the larger the initial shock, the lower the period ACAR. In other words, since investors in this contract appear to overreact to information contained in positive extreme events, this evidence suggest that investors overreact more to lower impact positive shocks. For the Gold Futures contract (Panel A) and the Robusta Coffee Futures contract (Panel B), there is no evidence at the 5 per cent level of significance to suggest that the abnormal returns are related to the size of the shock.

\section{TRADING STRATEGY BASED ON INVESTOR BEHAVIOUR}

An important question in any study of investor behaviour is whether any empirical findings can be applied in practice. In other words, if the detected patterns are real market inefficiencies, they must lead to abnormal returns. To this end, this sub-section investigates whether a trading strategy based on the findings of the paper could produce arbitrage profits. Suppose that a trader observes that investors in the IPE Brent Crude Oil Futures contract tend to overreact to positive shocks during the recent period (2000-2005) and decides to form a simple strategy in order to profit from this behaviour. He or she knows that after a positive market shock, investors, on average, will realise that they overreacted and reverse their behaviour. Thus, one strategy would be to sell the contract at the high price and buy it later when prices decrease. Based on the findings of the previous section, the trader will try to sell the contract at close on the day of the shock and buy it back at close ten days later. The trader could also borrow the cash needed for the margin and repay it ten 


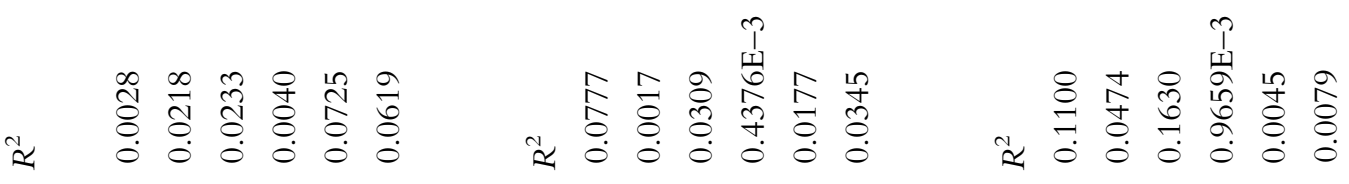

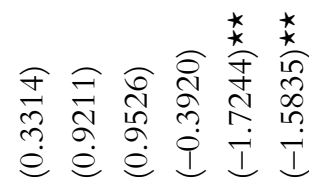

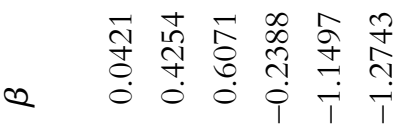

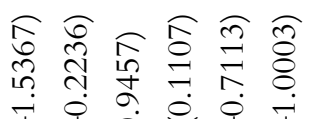

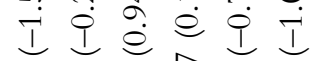

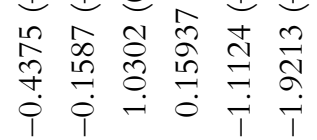

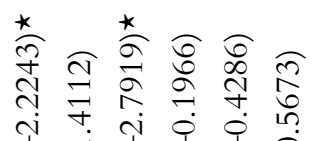

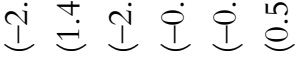

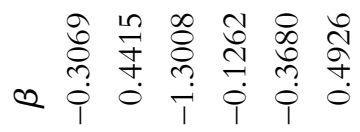

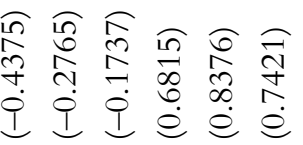

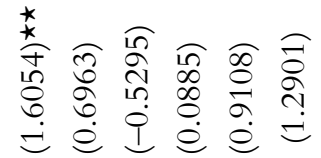

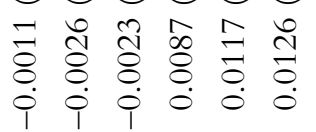

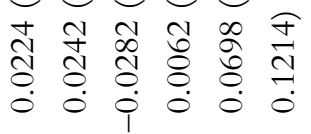

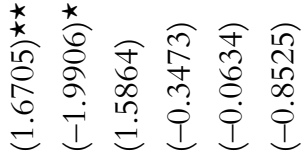

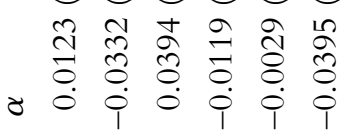

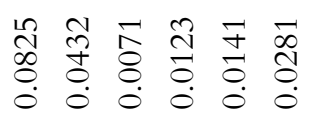

$$
\begin{aligned}
& \approx \text { そ) }
\end{aligned}
$$

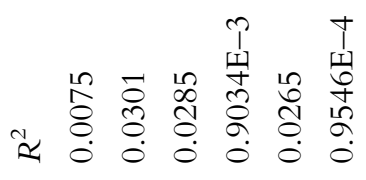

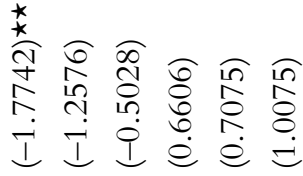

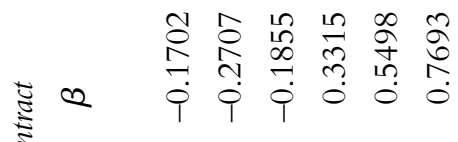

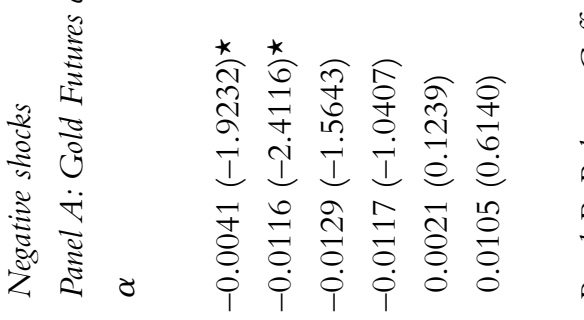

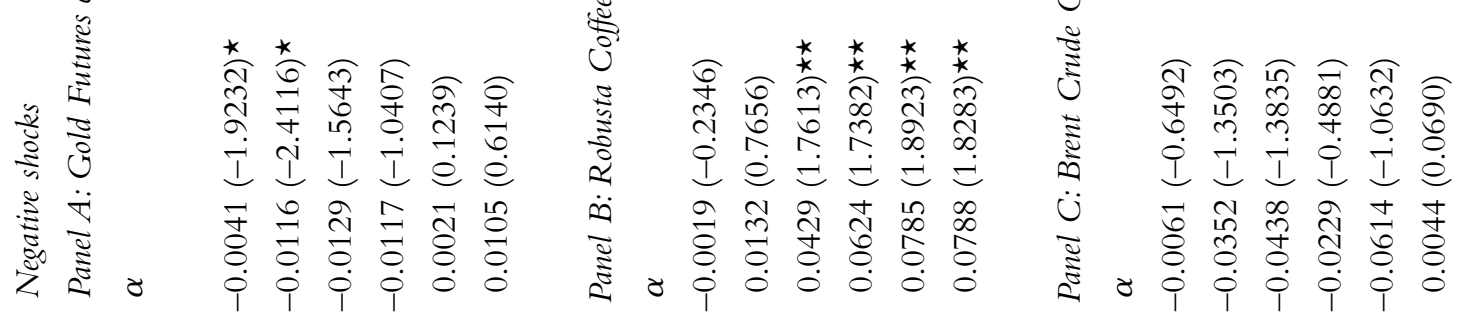

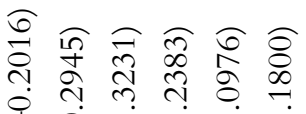

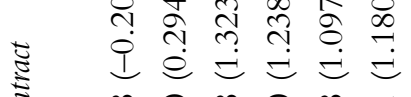

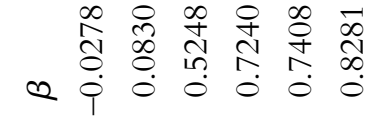

$$
\begin{aligned}
& \text { 竎 }
\end{aligned}
$$

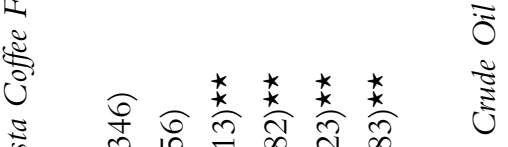

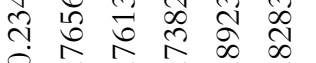

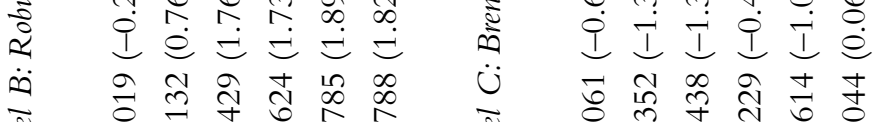

$$
\begin{aligned}
& \begin{array}{l}
\frac{1}{5} \\
\frac{0}{0} \\
\frac{1}{5} \\
0 \\
0 \\
\dot{m} \\
\frac{0}{0} \\
\frac{0}{10}
\end{array}
\end{aligned}
$$

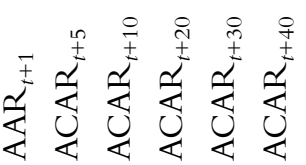

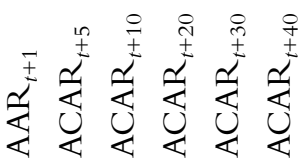

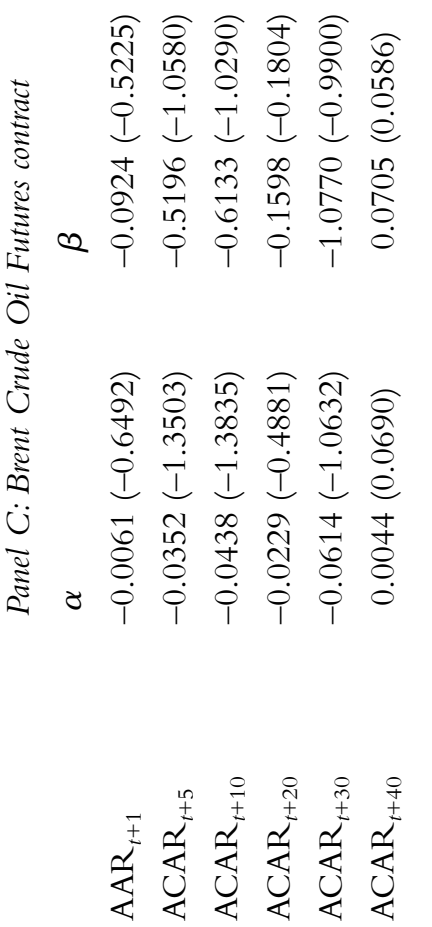


Table 4: Arbitrage profits from a trading strategy based on investor overreaction to positive extreme events: IPE Brent Crude Oil Futures contract (2000-2005)

\begin{tabular}{|c|c|c|c|c|c|}
\hline (1) & (2) & (3) & (4) & (5) & (6) \\
\hline Date of trade & Sell price ${ }^{a}$ & Buy price ${ }^{b}$ & $\begin{array}{l}\text { Gain from trade } \\
\text { in US } \$\end{array}$ & $\begin{array}{l}\text { Cost of borrowing } \\
\text { in US\$ }\end{array}$ & $\begin{array}{l}g \text { Net profit from total } \\
\text { position in US\$ } \$^{e}\end{array}$ \\
\hline 4/12/2000 & 23.12 & 23.33 & -210 & 1.284444 & -211.284 \\
\hline $6 / 12 / 2000$ & 31.21 & 30.39 & 820 & 1.733889 & 818.2661 \\
\hline $9 / 15 / 2000$ & 33.98 & 29.26 & 4,720 & 1.887778 & $4,718.112$ \\
\hline $1 / 19 / 2001$ & 27.04 & 28.1 & $-1,060$ & 1.502222 & -1061.5 \\
\hline $8 / 2 / 2001$ & 26.13 & 25.55 & 580 & 1.451667 & 578.5483 \\
\hline $1 / 4 / 2002$ & 22.18 & 18.41 & 3,770 & 1.232222 & $3,768.768$ \\
\hline $4 / 2 / 2002$ & 27.66 & 24.7 & 2,960 & 1.536667 & $2,958.463$ \\
\hline $12 / 23 / 2002$ & 29.72 & 30.77 & $-1,050$ & 1.651111 & $-1,051.65$ \\
\hline 9/24/2003 & 26.67 & 29.03 & $-2,360$ & 1.481667 & $-2,361.48$ \\
\hline $1 / 5 / 2004$ & 30.89 & 30.47 & 420 & 1.716111 & 418.2839 \\
\hline $1 / 19 / 2004$ & 30.57 & 31.83 & $-1,260$ & 1.698333 & $-1,261.7$ \\
\hline $5 / 24 / 2004$ & 38.17 & 35.67 & 2,500 & 2.120556 & $2,497.879$ \\
\hline $9 / 1 / 2004$ & 41.47 & 41.73 & -260 & 2.303889 & -262.304 \\
\hline $12 / 15 / 2004$ & 42.22 & 40.07 & 2,150 & 2.345556 & $2,147.654$ \\
\hline Total net profit & & & & & $11,696.05$ \\
\hline \multicolumn{6}{|c|}{$\begin{array}{l}{ }^{a} \text { Assuming the trader can sell at the closing price of the shock day. } \\
\text { b Assuming the trader can buy at close ten days later. } \\
\text { c Calculated as the difference between [sell price-buy price }] \times 1,000 \text { barrels (the size of one contract). } \\
\text { dAssuming initial capital of: [(sell price }) \times(\text { the size of the contract }(1,000 \text { barrels })) \times \text { initial margin }(10 \text { per } \\
\text { cent)] and an annual interest rate of } 2 \text { per cent for } 10 \text { days. }\end{array}$} \\
\hline
\end{tabular}

days later. Table 4 presents the gains and losses from this strategy for the 14 shock days that are identified in the paper for the period 2000-2005 (the results are for trading one contract). The first column reports the date of the shock, the second column reports the closing price on that day, the third column reports the closing price ten days after the shock, and the fourth column reports the gain from each trade calculated as the difference between the sell price and the buy price times 1,000 barrels (the size of one contract). The results indicate that, if the trader consistently followed the strategy for the five-year period, he or she would enjoy significant gains in 8 out of the 14 trades; furthermore the size of the gains is far more significant than the size of the losses.

Column 5 reports the cost of borrowing the cash needed to set up the strategy, 
assuming that the initial capital for each trade equals the sell price times the size of one contract (1,000 barrels) times an initial margin of 10 per cent and an annual interest rate of 2 per cent for ten days. For example, for the first trade it is supposed that one contract is worth $\$ 23,120$ $(\$ 23.12 \times 1,000$ barrels) and that the trader needs 10 per cent as a margin, ie $\$ 2,312$. Thus, the trader needs to borrow $\$ 2,312$ for ten days at 2 per cent, and the cost of borrowing is $\$ 1.284444$

$[2,312 \times(0.02 \times(10 / 360))]$. Finally, column 6 reports the net profit from the trader's position, ie the gain from the trade in the contract minus the cost of borrowing the funds. As discussed earlier, most trades are significantly profitable; the total net profit from all 14 trades over the five-year period is $\$ 11,696.05$ (on average, 2.8 trades per year). Put differently, the simple zero-investment strategy of shorting one contract for ten days after a market shock could generate an average net profit of $\$ 835.42$ per trade. Note also that, even if the interest rate is increased to 5 per cent and the margin to 20 per cent, the net profit would fall to $\$ 11,600.78$. This figure is far from zero and suggests that the pricing inefficiencies discussed above may be exploitable in practice.

\section{CONCLUSION}

Price reversals and momentum have been extensively studied for equity markets.

Relatively few studies, however, examine the reaction of investors to information in the futures market. Owing to leverage, lower transaction costs, better informed and more sophisticated participants, these markets should process information more efficiently than cash markets. This paper employs daily data between 1990 and 2005 and price shocks to proxy for the arrival of unobservable information and reports that investors in commodity futures contracts may, at times, overreact or underreact to the information contained in extreme market events. Furthermore, a trading strategy for the IPE Brent Crude Oil Futures contract generates significant arbitrage profits, indicating that these pricing inefficiencies may be exploitable in practice.

\section{References and Notes}

1 DeBondt, W. F.M. and Thaler, R. H. (1985) 'Does The Stock Market Overreact?' Journal of Finance, Vol. 40, pp. 793-805.

2 Jegadeesh, N. (1990) 'Evidence of Predictable Behavior of Security Returns', Journal of Finance, Vol. 45, pp. 881-898.

3 Baytas, A. and Cakici, N. (1999) 'Do Markets Overreact? International Evidence', Journal of Banking and Finance, Vol. 23, pp. 1121-1144.

4 Lasfer, M. A., Melnik, A. and Thomas, D. C. (2003) 'Short Term Reaction of Stock Markets in Stressful Circumstances', Journal of Banking and Finance, Vol. 27, pp. 1959-1977.

5 Barberis, N., Schleifer, A. and Vishny, R. (1998) 'A Model of Investor Sentiment', Journal of Financial Economics, Vol. 49, pp. 307-343.

6 These studies are based on evidence of empirical psychology that individuals tend at times to underreact or overreact; see Griffin, D. and Tversky, A. (1992) 'The Weighting of Evidence and the Determinants of Overconfidence', Cognitive Psychology, Vol. 24, pp. 411-435.

7 Fung, A. K.-W., Mok, D. M. Y. and Lam, K. (2000) 'Intraday Price Reversals for Index Futures in the US and Hong-Kong', Journal of Banking and Finance, Vol. 24, pp. 1179-1201.

8 Ederington, L. H. and Lee, J. H. (1995) 'The Short-Run Dynamics of the Price Adjustment to New Information', Journal of Financial and Quantitative Analysis, Vol. 30, pp. 117-134.

9 Gay, G. D., Kale, J. R., Kolb, R. W. and Noe, 
T. H. (1994) 'Micro Fads in Asset Prices: Evidence from the Futures Markets', Journal of Futures Markets, Vol. 14, pp. 637-659.

10 Grant, J. F., Wolf, A. and Wo, S. (2005) 'Intraday Price Reversals in the US Stock Index Futures Markets: a 15-Year Study', Journal of Banking and Finance, Vol. 29, pp. 1311-1327.

11 Although these reversals are reduced when gross trading results are adjusted with a bid-ask proxy for transactions costs.

12 See also Schnusenberg, O. and Madura, J. (2001)

'Do U.S. Stock Market Indexes Over- Or

Underreact?', Journal of Financial Research, Vol. 24, pp. 179-204.

13 If a shock occurs within the first 15 trading days from a previous shock, it is included in the ACARs of the previous shock and is not considered as a new shock day. 